\title{
Synthesis and Crystal Structures of Two Metal Complexes Incorporating Malonate and Organodiamine Ligands
}

\author{
Quan-Zheng Zhang, Wen-Bin Yang, Shu-Mei Chen, and Can-Zhong Lu* \\ Fujian Institute of Research on the Structure of Matter, Chinese Academy of Sciences, Fuzhou 350002, P.R. China \\ "E-mail:czlu@ms.fjirsm.ac.cn \\ Received June 7, 2005
}

Key Words : Malonate, Organodiamine ligand, Crystal structure

Investigation on novel organic-inorganic hybrid framework assemblies represents one of the most active areas of material science and chemical research. ${ }^{1-3}$ Major advances have been made in these materials due to their interesting properties and potential in various applications, e.g., electrical conductivity, magnetism, host-guest chemistry, ion exchange, catalysis, nonlinear optics, etc. ${ }^{4-6}$ Moreover, discovery and design of such new materials with specific networks remain of a particularly important and active subject in the field of supramolecuar chemistry and crystal engineering.

A variety of complexes with interesting compositions and topologies have been prepared through taking certain factors into account, such as the coordination nature of the metal ion and the shape, functionality, flexibility, and symmetry of organic ligand. Recently, some dicarboxylate ligands, such as oxalate, malonate, and terephthalate, have been widely used in the construction of these interesting structures. ${ }^{5-13}$ Among them, the malonate dianion can function as a versatile bridging ligand, and the complexity of its structure is associated with the simultaneous adoption of chelating bidentate and different carboxylate bridging coordination modes like syn-syn, syn-anti and anti-anti. On the other hand, an example of the advance in the field of supramolecular chemistry and crystal engineering is the generation of polymeric structures by applying carboxylate bridging ligands together with organodiamine ligands (such as 4,4'-, 2,2'-bypyridine and 1,10-phenanthroline). A larger number of this type of complexes have been synthesized and characterized recently, whereas the structural chemistry of metal complexes incorporating mixed malonate and organodiamine ligands has been less studied. ${ }^{14-27}$

In the present work we report the synthesis and X-ray crystal structures of two new malonato complexes incorporating organodiamine ligands: $\left[\mathrm{Ni}(\right.$ phen $\left.)(\mathrm{mal})\left(\mathrm{H}_{2} \mathrm{O}\right)_{2}\right] \cdot 3 \mathrm{H}_{2} \mathrm{O}$ $\left(\mathrm{H}_{2} \mathrm{mal}=\right.$ malonic acid, phen $=1,10$-phenanthroline $)(\mathbf{1})$ and $\left[\mathrm{Zn}(\mathrm{bpy})\left(\mathrm{H}_{2} \mathrm{O}\right)\right]_{2}\left[\mathrm{Zn}(\mathrm{bpy})(\mathrm{mal})\left(\mathrm{H}_{2} \mathrm{O}\right)_{2}\right]_{2}\left(\mathrm{NO}_{3}\right)_{4} \cdot 4 \mathrm{H}_{2} \mathrm{O}($ bpy $=$ 2,2'-bipyridine) (2).

\section{Experimental Section}

Materials. All chemicals used during the course of this work were of reagent grade and were used as received from commercial source without further purification. Elemental analyses $(\mathrm{C}, \mathrm{H}, \mathrm{N})$ were performed with a Vario EL III CHNOS Elemental Analyzer. IR spectra were recorded from
$\mathrm{KBr}$ pellets in the range of $4000-400 \mathrm{~cm}^{-1}$ on a FTS-40 spectrophotometer. Fluorescence spectrum was carried out on a FLS920 spectrometer. Thermogravimetric analyses were performed on a NETZSCH STA 449C instrument in

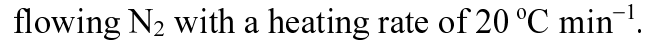

Synthesis of $\left[\mathrm{Ni}(\mathrm{phen})(\mathrm{mal})\left(\mathrm{H}_{2} \mathrm{O}\right)_{2}\right] \cdot 3 \mathrm{H}_{2} \mathrm{O}$. An ethanol solution $(5 \mathrm{~mL})$ of 1,10 -phenanthroline hydrate $(0.2 \mathrm{~g}, 1$ mmol) was added slowly to an aqueous solution $(10 \mathrm{~mL})$ of $\mathrm{NiCl}_{2} \cdot 6 \mathrm{H}_{2} \mathrm{O}(0.35 \mathrm{~g}, 1.5 \mathrm{mmol})$ with continuous stirring. An aqueous solution $(10 \mathrm{~mL})$ of malonic acid $(1.14 \mathrm{~g}, 1.1$ mmol), adjusted to $\mathrm{pH}$ value about 5 with an aqueous $\mathrm{NaOH}$ solution $(1 \mathrm{~N})$, was then added slowly to the above reaction mixture with continuous stirring. After half an hour, the reaction mixture was allowed to stand at room temperature undisturbed for three weeks, resulting in blue crystals (yield: $68.5 \%$, based on Ni). (Found: C, 41.86; H, 4.73; N, 6.46\%. Calc. for $\mathrm{C}_{15} \mathrm{H}_{20} \mathrm{~N}_{2} \mathrm{O}_{9} \mathrm{Ni}$ : C, 41.80; H, 4.68; N, 6.5\%). IR (KBr pellet, $\mathrm{cm}^{-1}$ ): 3354 (s), 1614 (s), 1562 (s), 1427 (s), $1381(\mathrm{~m}), 1263(\mathrm{~m}), 1146(\mathrm{w}), 854$ (s), 727 (s).

Synthesis of $\left[\mathrm{Zn}(\mathrm{bpy})\left(\mathrm{H}_{2} \mathrm{O}\right)\right]_{2}\left[\mathrm{Zn}(\mathrm{bpy})(\mathrm{mal})\left(\mathrm{H}_{2} \mathrm{O}\right)_{2}\right]_{2}-$ $\left(\mathrm{NO}_{3}\right)_{4} \cdot \mathbf{4 H}_{2} \mathrm{O}$. The procedure was similar to the synthesis of the compound $\left[\mathrm{Ni}(\right.$ phen $\left.)(\mathrm{mal})\left(\mathrm{H}_{2} \mathrm{O}\right)_{2}\right] \cdot 3 \mathrm{H}_{2} \mathrm{O}$, except that 2,2'-bipyridine $(0.16 \mathrm{~g}, 1 \mathrm{mmol})$ and $\mathrm{Zn}\left(\mathrm{NO}_{3}\right)_{2} \cdot 6 \mathrm{H}_{2} \mathrm{O}(0.30$ $\mathrm{g}, 1.0 \mathrm{mmol})$ were used instead of 1,10-phenanthroline hydrate and $\mathrm{NiCl}_{2} \cdot 6 \mathrm{H}_{2} \mathrm{O}$ (yield: $51.7 \%$, based on $\mathrm{Zn}$ ). (Found: C, 36.34; H, 3.81; N, 11.11\%. Calc. for $\mathrm{C}_{46} \mathrm{H}_{56} \mathrm{~N}_{12} \mathrm{O}_{30} \mathrm{Zn}_{4}$ : C, 36.38; H, 3.72; N, 11.07\%). IR ( $\mathrm{KBr}$ pellet, $\left.\mathrm{cm}^{-1}\right)$ : 3386 (s), 1615 (s), 1599 (s), 1566 (s), 1475 (m), 1444 (m), 1385 (s), 1265 (m), 1157 (w), 1024 (w), 768 (s), 735 (m), 654 (w).

Intensity data from the compounds $\mathbf{1}$ and $\mathbf{2}$ were collected at room temperature on a computer-controlled MercuryCCD diffractometer equipped with graphite monochromated Mo-K $\alpha$ radiation $(\lambda=0.71073 \AA$ ). The structures were solved by direct methods, successive Fourier difference synthesis and refined by the full matrix least-squares based on $\mathrm{F}^{2}$ using the SHELXTL-97 program package. In all cases, all nonhydrogen atoms were refined anistropically. In compound 1, all hydrogen atoms were generated from difference Fourier map and refined with isotropic temperature factors. In compound 2, the organic hydrogen atoms were generated geometrically, while the aqua hydrogen atoms were not located. The crystallographic data for $\mathbf{1}$ and $\mathbf{2}$ are listed in Table 1. Selected bond lengths and angles are given in Table 2. CCDC-269356 for $\mathbf{1}$ and CCDC-269357 for $\mathbf{2}$ contain the supplementary crystallographic data for this paper. Copies of 
Table 1. Crystal data and structure refinement parameters for compounds $\mathbf{1}$ and $\mathbf{2}$

\begin{tabular}{|c|c|c|}
\hline & 1 & 2 \\
\hline Empirical formula & $\mathrm{C}_{15} \mathrm{H}_{20} \mathrm{~N}_{2} \mathrm{O}_{9} \mathrm{Ni}$ & $\mathrm{C}_{46} \mathrm{H}_{56} \mathrm{~N}_{12} \mathrm{O}_{30} \mathrm{Zn}_{4}$ \\
\hline Molecule weight & 431.04 & 1518.51 \\
\hline Crystal system & Monoclinic & Triclinic \\
\hline Space group & $P 2 / \mathrm{n}$ & $P 1$ \\
\hline$a(\AA)$ & $8.9413(10)$ & $10.787(3)$ \\
\hline$b(\AA)$ & $12.1606(10)$ & $11.602(3)$ \\
\hline$c(\AA)$ & $9.4343(9)$ & $14.244(4)$ \\
\hline$\alpha\left({ }^{\circ}\right)$ & & $110.584(3)$ \\
\hline$\beta\left({ }^{\circ}\right)$ & $116.260(3)$ & $91.9410(10)$ \\
\hline$\gamma\left({ }^{\circ}\right)$ & & $109.711(2)$ \\
\hline$V\left(\AA^{3}\right)$ & $919.94(15)$ & $1547.3(7)$ \\
\hline $\mathrm{Z}$ & 2 & 1 \\
\hline$D_{\mathrm{C}}\left(\mathrm{g} \mathrm{cm}^{-3}\right)$ & 1.556 & 1.630 \\
\hline$F(000)$ & 448 & 776 \\
\hline$\mu\left(\mathrm{mm}^{-1}\right)$ & 1.106 & 1.630 \\
\hline Flack parameter & & $0.339(9)$ \\
\hline Goodness of fit on $\mathrm{F}^{2}$ & 1.063 & 1.029 \\
\hline $\begin{array}{l}\text { Largest diff. Peak and } \\
\text { hole }\left(\mathrm{e} \AA^{-3}\right)\end{array}$ & 0.562 and -0.581 & 0.387 and -0.581 \\
\hline Final $\mathrm{R}$ indices & $R 1=0.0277$ & $R 1=0.0359$ \\
\hline$[\mathrm{I}>2 \operatorname{sigma}(\mathrm{I})]^{a}$ & $w R 2=0.0728$ & $w R 2=0.0996$ \\
\hline
\end{tabular}

${ }^{a} \mathrm{R} 1=\Sigma\left(\left|\mathrm{F}_{0}\right|-\left|\mathrm{F}_{\mathrm{C}}\right|\right) / \Sigma\left|\mathrm{F}_{0}\right| . \mathrm{wR} 2=\left[\Sigma \mathrm{w}\left(\mathrm{F}_{0}{ }^{2}-\mathrm{F}_{\mathrm{C}}{ }^{2}\right)^{2} / \Sigma \mathrm{W}\left(\mathrm{F}_{0}{ }^{2}\right)^{2}\right]^{0.5}$

Table 2. Selected bond lengths ( $\AA$ ) for $\mathbf{1}$ and $\mathbf{2}$

\begin{tabular}{llll}
\hline Atoms & Distance & Atoms & Distance \\
\hline Compound 1 & & & \\
$\mathrm{Ni}(1)-\mathrm{O}(1)$ & $2.0073(11)$ & $\mathrm{Ni}(1)-\mathrm{O}(3)$ & $2.1102(12)$ \\
$\mathrm{Ni}(1)-\mathrm{N}(1)$ & $2.0692(12)$ & & \\
Compound 2 & & & \\
$\mathrm{Zn}(1)-\mathrm{O}(3)$ & $2.056(3)$ & $\mathrm{Zn}(3)-\mathrm{O}(8)$ & $2.051(3)$ \\
$\mathrm{Zn}(1)-\mathrm{O}(2)$ & $2.066(4)$ & $\mathrm{Zn}(3)-\mathrm{O}(11)$ & $2.096(3)$ \\
$\mathrm{Zn}(1)-\mathrm{O}(4)$ & $2.084(3)$ & $\mathrm{Zn}(3)-\mathrm{N}(6)$ & $2.106(4)$ \\
$\mathrm{Zn}(1)-\mathrm{N}(2)$ & $2.123(4)$ & $\mathrm{Zn}(3)-\mathrm{O}(10)$ & $2.133(4)$ \\
$\mathrm{Zn}(1)-\mathrm{O}(1)$ & $2.139(4)$ & $\mathrm{Zn}(3)-\mathrm{N}(5)$ & $2.140(4)$ \\
$\mathrm{Zn}(1)-\mathrm{N}(1)$ & $2.162(5)$ & $\mathrm{Zn}(3)-\mathrm{O}(9)$ & $2.144^{`}(4)$ \\
$\mathrm{Zn}(2)-\mathrm{O}(7)$ & $2.014(3)$ & $\mathrm{Zn}(4)-\mathrm{O}(12)$ & $2.025(3)$ \\
$\mathrm{Zn}(2)-\mathrm{O}(5)$ & $2.049(3)$ & $\mathrm{Zn}(4)-\mathrm{O}(13)$ & $2.071(5)$ \\
$\mathrm{Zn}(2)-\mathrm{O}(6)$ & $2.053(4)$ & $\mathrm{Zn}(4)-\mathrm{N}(7)$ & $2.098(4)$ \\
$\mathrm{Zn}(2)-\mathrm{N}(4)$ & $2.116(4)$ & $\mathrm{Zn}(4)-\mathrm{N}(8)$ & $2.115(5)$ \\
$\mathrm{Zn}(2)-\mathrm{N}(3)$ & $2.137(5)$ & & \\
\hline
\end{tabular}

the data can be obtained free of charge on application to CCDC, 12 Union Road, Cambridge CB2 1EZ, UK (Fax: (+44) 1223-336-033; e-mail: deposit@ccdc.cam.ac.uk).

\section{Results and Discussion}

Figure 1 presents a thermal ellipsoid plot of molecular structure of $\mathbf{1}$, showing the atom-labeling scheme used. Ni atom is coordinated by two nitrogen atoms from a phen molecule, two oxygen atoms from two carboxylate groups of malonate ligand, and two oxygen atoms from two water molecules, respectively. One slightly distorted octahedron $\left\{\mathrm{NiN}_{2} \mathrm{O}_{4}\right\}$ is formed, in which the basal plane is defined by two carboxyl oxygen and two phen nitrogen atoms with

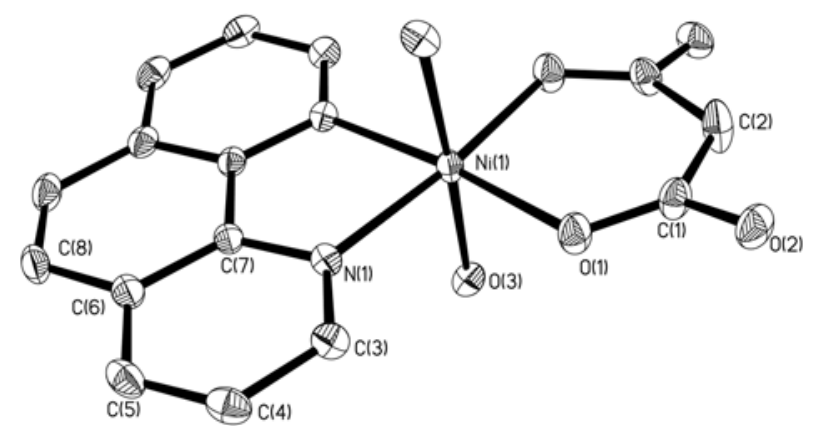

Figure 1. The molecular structure of $\mathbf{1}$, showing the atom-labeling scheme and 30\% thermal ellipsoids. Lattice water molecules and all $\mathrm{H}$ atoms are omitted for clarity.

mean deviation of $0.0267 \AA$, and the corresponding axial sites are occupied by two water molecules with Ni-O distances of 2.1102(12) A. Phen molecule is essentially planar in $\left[\mathrm{Ni}(\mathrm{phen})(\mathrm{mal})\left(\mathrm{H}_{2} \mathrm{O}\right)_{2}\right]$ unit, the maximum atomic deviation being $0.0252 \AA$ from atom $\mathrm{C}(6)$. Malonate dianion chelates to the $\mathrm{Ni}$ atom through two carboxyl oxygen atoms with Ni-O distance of 2.0073(11) A. The malonate is not planar with the maximum atomic deviation of $0.2329 \AA$ from atom $\mathrm{O}(1)$, and the dihedral angle between two carboxylate groups is $20.1^{\circ}$. In the malonate dianion, the $\mathrm{C}(1)-\mathrm{C}(2)-\mathrm{C}(1 \mathrm{~A})$ (symmetry code: $\mathrm{A}-\mathrm{x}+7 / 2, \mathrm{y},-\mathrm{z}+3 / 2$ ) bond angle is $123.8(3)^{\circ}$, which is comparable to that in two Ni malonate complexes reported recently. ${ }^{28,29}$

It is noteworthy that there exist two kinds of hydrogen bonding in the crystal structure: one is happened between the uncoordinated carboxyl oxygen atoms $(\mathrm{O} 2)$ and the coordinated water molecules $(\mathrm{O} 3)$ with $\mathrm{O} \cdots \mathrm{O}$ distances of 2.755(2) $\AA$, while the other is between the uncoordinated carboxyl oxygen atoms and the lattice water molecules $(\mathrm{O} 4, \mathrm{O} 5)$ with $\mathrm{O} \cdots \mathrm{O}$ distances of $2.848(2)$ and 2.899(2) $\AA$, respectively (Table 3 ). Thus, the discrete $\mathrm{Ni}($ phen)(mal)$\left.\left(\mathrm{H}_{2} \mathrm{O}\right)_{2}\right]$ units are bound together through $\mathrm{O} 3-\mathrm{H} \cdots \mathrm{O} 2$ hydrogen bonding to a one-dimensional chain along the a axis (Fig. 2). Moreover, the one-dimensional structure is further connected to a three-dimensional network through $\mathrm{O} 4-\mathrm{H} \cdots \mathrm{O} 2$ and $\mathrm{O} 5-\mathrm{H} \cdots \mathrm{O} 2$ hydrogen bonding.

The compound 2 displays non-centrosymmetric structure, consisting of uncoordinated nitrate anions, one-dimensional cationic zinc chains containing four crystallographically independent zinc atoms and free water molecules (Fig. 3). The four crystallographically independent zinc atoms exhibit two types of coordination surroundings: one is slightly distorted trigonal bipyramidal geometry $\left\{\mathrm{ZnN}_{2} \mathrm{O}_{3}\right\}$

Table 3. Hydrogen bonding interactions in $\mathbf{1}$

\begin{tabular}{cccccc}
\hline \multirow{2}{*}{ D-H $\cdots \mathrm{A}$} & \multicolumn{3}{c}{$\mathrm{d}(\AA)$} & & Angle $\left({ }^{\circ}\right)$ \\
\cline { 2 - 4 } & $\mathrm{D}-\mathrm{H}$ & $\mathrm{H} \cdots \mathrm{A}$ & $\mathrm{D} \cdots \mathrm{A}$ & $\mathrm{DHA}$ \\
\hline $\mathrm{O}(4)-\mathrm{H}(4 \mathrm{~A}) \cdots \mathrm{O}(2)$ & $0.78(2)$ & $2.07(2)$ & $2.846(2)$ & & $172(3)$ \\
$\mathrm{O}(5)-\mathrm{H}(5 \mathrm{~B}) \cdots \mathrm{O}(2)$ & $0.81(3)$ & $2.10(3)$ & $2.900(2)$ & & $174(3)$ \\
$\mathrm{O}(3)-\mathrm{H}(3 \mathrm{~B}) \cdots \mathrm{O}(2)$ & $0.82(2)$ & $1.94(2)$ & $2.756(2)$ & $170(2)$ \\
\hline
\end{tabular}

Symmetry transformations used to generate equivalent atoms: ${ }^{\mathrm{A}} \mathrm{x}-1, \mathrm{y}$, $\mathrm{z} ;{ }^{\mathrm{B}} \mathrm{x}-1 / 2,-\mathrm{y}+1, \mathrm{z}+1 / 2 ;{ }^{\mathrm{C}}-\mathrm{x}+4,-\mathrm{y}+1,-\mathrm{z}+2$ 


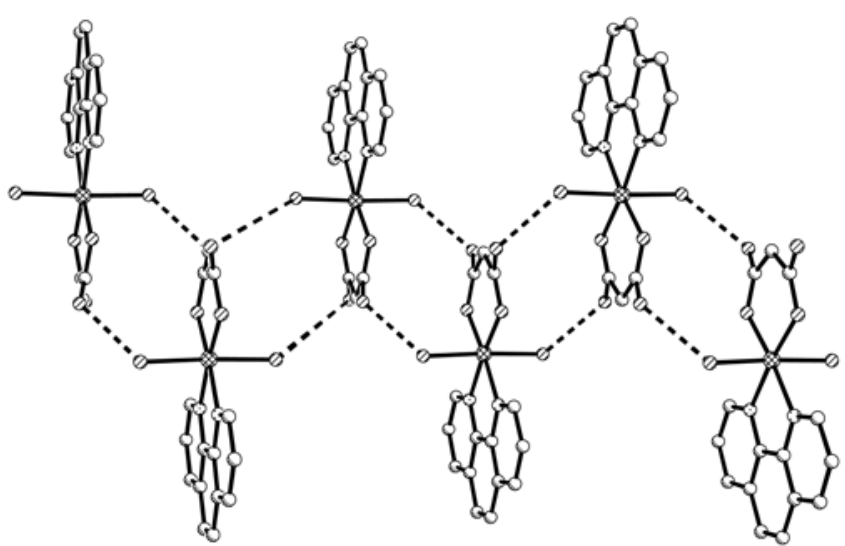

Figure 2. Discrete $\left[\mathrm{Ni}(\mathrm{phen})(\mathrm{mal})\left(\mathrm{H}_{2} \mathrm{O}\right)_{2}\right]$ units are bound together through $\mathrm{O} 3-\mathrm{H} \cdots \mathrm{O} 2$ hydrogen bonding to a one-dimensional chain along the $a$ axis.

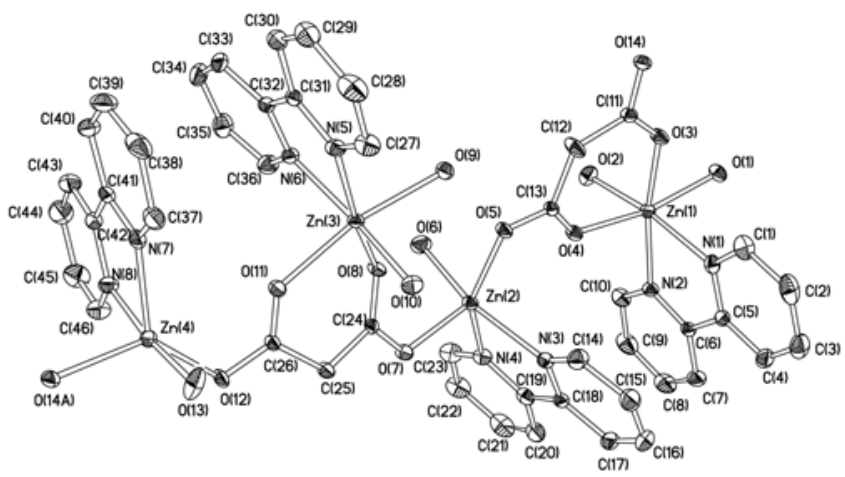

Figure 3. Asymmetry unit of (2), showing the atom-labeling scheme and $30 \%$ thermal ellipsoids.

$(\mathrm{Zn}(2)$ and $\mathrm{Zn}(4))$, while the other is slightly distorted octahedral geometry $\left\{\mathrm{ZnN}_{2} \mathrm{O}_{4}\right\}(\mathrm{Zn}(1)$ and $\mathrm{Zn}(3))$. In the trigonal bipyramidal geometries, the basal plane is defined by one bpy nitrogen and two carboxyl oxygen atoms with the average $\mathrm{Zn}-\mathrm{N}$ distance of 2.107(4) $\AA$ and $\mathrm{Zn}-\mathrm{O}$ distance of 2.045(3) $\AA$, respectively; the apical sites are occupied by one bpy nitrogen and one coordinated water molecule with the average $\mathrm{Zn}-\mathrm{N}$ distance of 2.126(5) $\AA$ and $\mathrm{Zn}-\mathrm{O}$ distance of 2.062(5) $\AA$, respectively. In the octahedral geometry, a basal plane is defined by two bpy nitrogen atoms, one coordinated water molecule and one carboxyl oxygen atom, while the apical sites are occupied by one water molecule and one carboxyl oxygen atom, respectively. The average $\mathrm{Zn}-\mathrm{N}, \mathrm{Zn}-\mathrm{O}_{\mathrm{w}}, \mathrm{Zn}-\mathrm{O}_{\text {carb }}$ distances are 2.142(5), 2.103(4) and 2.070(3) $\AA$ for $\mathrm{Zn}(1)$ center, while the corresponding values are 2.123(4), 2.138(4) and 2.074(3) $\AA$ for $Z n(3)$ center.

In $\left[\mathrm{Zn}(\right.$ bpy $\left.)(\mathrm{mal})\left(\mathrm{H}_{2} \mathrm{O}\right)_{2}\right]$ units $(\mathrm{Zn}(1)$ and $\mathrm{Zn}(3))$, each malonate group adopts simultaneously bidentate (at $\mathrm{Zn}((1)$ and $\mathrm{Zn}(3)$ ) and monodentate (at $\mathrm{Zn}(2)$ and $\mathrm{Zn}(4)$ ) coordination modes. Previous report has shown that the malonate has a highly conformational flexibility (envelope, skew boat, boat and chair). ${ }^{30}$ In our case, it should be pointed out that in $\mathrm{Zn}(1)$ center the chelate malonate ring is nearly planar (the maximum atomic deviation of $-0.029 \AA$ from $\mathrm{C}(11)$ ), while in $\mathrm{Zn}(3)$ center the chelate malonate ring adopts a skew boat conformation (the maximum atomic deviation of $-0.248 \AA$ from $\mathrm{O}(8)$ ). The average $\mathrm{C}-\mathrm{O}$ distances and O-C-O bond angles are 1.254(5) $\AA$ and $121.8(5)^{\circ}$ in $\mathrm{Zn}(1)$ center, which are comparable to those in $\mathrm{Zn}(3)$ center $\left(1.252(5) \AA\right.$ and $\left.121.8(4)^{\circ}\right)$. The $\mathrm{C}(11)-\mathrm{C}(12)-$ $\mathrm{C}(13)$ and $\mathrm{C}(24)-\mathrm{C}(25)-\mathrm{C}(26)$ bond angles are 121.6(4) and $119.9(3)^{\circ}$, respectively, which are slightly smaller than the corresponding bond angle found in compound 1 . In the molecular structure, each of the four crystallographically independent bpy molecules is nearly planar, with the largest atomic deviation of $0.0709 \AA$ from the corresponding leastsquares plane. The dihedral angle between two bpy rings in $\mathrm{Zn}(1)$ and $\mathrm{Zn}(2)$ centers is $15.6^{\circ}$, in $\mathrm{Zn}(3)$ and $\mathrm{Zn}(4)$ centers is $18.1^{\circ}$, while in $\mathrm{Zn}(2)$ and $\mathrm{Zn}(3)$ centers is $6.7^{\circ}$.

As shown in Figure 4, the one-dimensional cationic zinc chain contains a regular alternation of $\left[\mathrm{Zn}(\mathrm{bpy})(\mathrm{mal})\left(\mathrm{H}_{2} \mathrm{O}\right)_{2}\right]$ $(\mathrm{Zn}(1)$ and $\mathrm{Zn}(3))$ and $\left[\mathrm{Zn}(\mathrm{bpy})\left(\mathrm{H}_{2} \mathrm{O}\right)\right](\mathrm{Zn}(2)$ and $\mathrm{Zn}(4))$ units, running along the $c$ axis. The structure can also be described as the alternate $\left[\mathrm{Zn}(\mathrm{bpy})\left(\mathrm{H}_{2} \mathrm{O}\right)_{2}\right]$ and $[\mathrm{Zn}(\mathrm{bpy})-$ $\left(\mathrm{H}_{2} \mathrm{O}\right)$ ] units are linked up by malonate dianions to a onedimensional chain. In this one-dimensional structure, the adjacent zinc atoms are linked up through carboxylate groups in a syn-anti mode, and the intrachain zinc $\cdots$ zinc separations through the carboxylate bridge are 4.783(2) $(\mathrm{Zn}(1) \cdots \mathrm{Zn}(2)), 4.804(2)(\mathrm{Zn}(3) \cdots \mathrm{Zn}(4)), 4.812(5)(\mathrm{Zn}(2)$ $\cdots \operatorname{Zn}(3))$ and $4.507(6) \AA(Z n(1) \cdots Z n(4 C)$, symmetry code: $\mathrm{C} x, y, 1+z)$, whereas those through malonato bridge are 8.160(6) $(\mathrm{Zn}(2) \cdots \mathrm{Zn}(4))$ and 8.043(8) $\AA(\mathrm{Zn}(2) \cdots \mathrm{Zn}(4 \mathrm{C}))$.

It is worthwhile that an extensive network of hydrogen bonding involving the coordinated water molecules, four

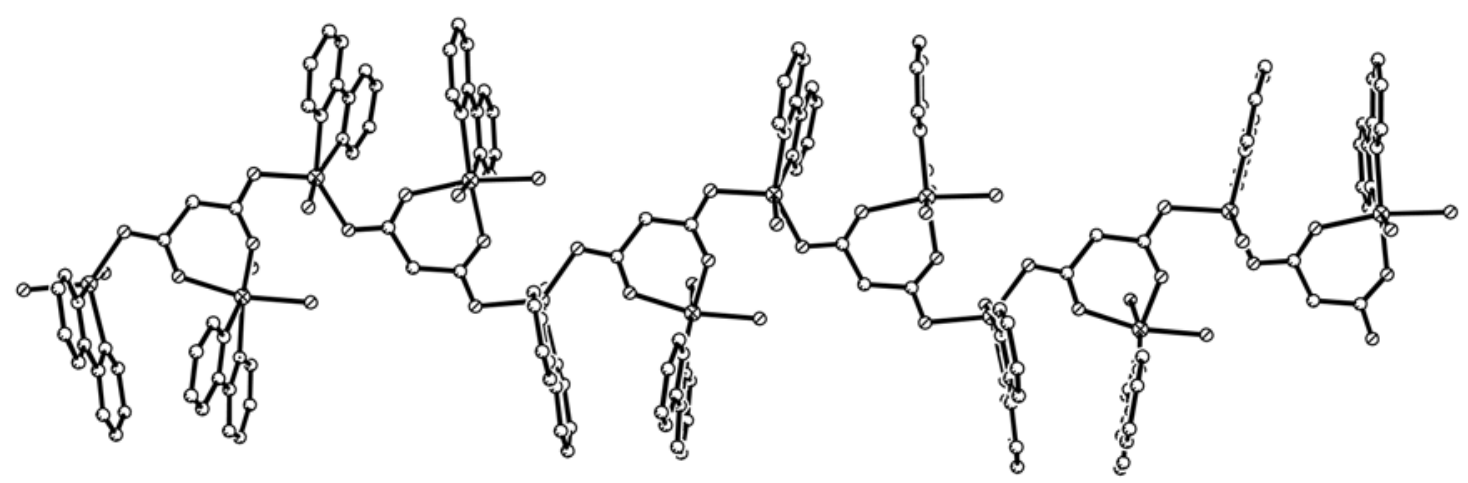

Figure 4. One-dimensional cationic zinc chain contains a regular alternation of $\left[\mathrm{Zn}(\mathrm{bpy})(\mathrm{mal})\left(\mathrm{H}_{2} \mathrm{O}\right)_{2}\right](\mathrm{Zn}(1)$ and $\mathrm{Zn}(3))$ and $\left[\mathrm{Zn}(\mathrm{bpy})\left(\mathrm{H}_{2} \mathrm{O}\right)\right](\mathrm{Zn}(2)$ and $\mathrm{Zn}(4))$ units running along the $c$ axis. 
nitrate anions and lattice water molecules contribute much to the stabilization of the crystal structure. The one-dimensional cationic zinc chains are bound together through hydrogen bonding to two-dimensional layers, and the layers are further contacted to a three-dimensional network through these weak interactions.

Recently two related $\mathrm{Cu}$ complexes have been reported. ${ }^{27}$ The two complexes are made up of uncoordinated perchlorate anions and malonate-bridged zigzag copper chains grouped in an isosceles triangle running along the $b$ and $c$ axes. In the two structures, all the $\mathrm{Cu}$ atoms are fivecoordinated in a distorted square pyramidal geometry. Each malonate dianion links $\left[\mathrm{Cu}(\mathrm{bpy})\left(\mathrm{H}_{2} \mathrm{O}\right)\right]$ units through its OCCCO skeleton in the anti-anti conformation while through its OCO carboxylate bridges in the syn-anti mode. Like that in these two complexes, the malonate dianion exhibits similar coordination modes in the complex 2 . However, a striking feature is that the two metal ions exhibit different coordination environments $\left(\left\{\mathrm{ZnN}_{2} \mathrm{O}_{3}\right\}\right.$ and $\left.\left\{\mathrm{ZnN}_{2} \mathrm{O}_{4}\right\}\right)$ in the present complex.

The compounds $\mathbf{1}$ and $\mathbf{2}$ were prepared in similar reaction condition, however, their structures are markedly different. The metal atom in $\mathbf{1}$ is coordinated by two carboxyl oxygen, two phen $\mathrm{N}$ atoms and two water molecules, displaying octahedral coordination geometry. While the metal atoms $(\mathrm{Zn}(2)$ and $\mathrm{Zn}(4))$ in $\mathbf{2}$ are coordinated by two carboxyl oxygen, two bpy $\mathrm{N}$ atoms and one water molecule, respectively, displaying trigonal bipyramidal geometry. On the other hand, the coordination mode of malonate dianion plays an important role in the formation of the structures. In $\mathbf{1}$, the dianion adopts chelating bidentate coordination, while in 2 the dianion displays tetra-dentate coordination. Obviously, the tetra-dentate coordination is more helpful to form polymeric structure.

The thermo-gravimetric analyses (TG) were carried out in 30-800 ${ }^{\circ} \mathrm{C}$ for both complexes. The results show that the complex 1 exhibits three key steps of weight loss while the complex 2 exhibits two key steps of weight loss. The first step occurs in the range of $75-170{ }^{\circ} \mathrm{C}$ for 1 and $55-150{ }^{\circ} \mathrm{C}$ for 2, corresponding to the removal of all the water molecules. The observed weight losses are $20.83 \%$ for 1 and $11.78 \%$ for 2, which are consistent with the calculated results $20.88 \%$ for 1 and $11.86 \%$ for 2 , respectively. The last two steps taking place in $240-800{ }^{\circ} \mathrm{C}$ for $\mathbf{1}$ should correspond to the release of coordinated water and organic ligands (calc. $64 \%$ ). However, the observed weight loss $(41.9 \%)$ is lower than the predicted value. This is due to the retention of some carbonaceous residue in the final solid phase (black in color). The second weight loss for $\mathbf{2}$ is in $200-340{ }^{\circ} \mathrm{C}$, corresponding to the departure of coordinated water and organic configuration (calc. $61.9 \%$, found $62.2 \%$ ).

Fluorescent analysis of the complex 2 was performed at room temperature in solid state. The result shows that the complex exhibits a photoluminescence at $456 \mathrm{~nm}\left(\lambda_{\mathrm{ex}}=380\right.$ $\mathrm{nm})$. It is known that the free 2,2'-bypyridine ligand has a weak luminescence at $c a .525 \mathrm{~nm}$ in the solid state at room temperature. To understand the nature of this emission band, we analyzed the fluorescent property of free malonate, confirming that it has no emission in the 400-800 $\mathrm{nm}$ range. The fact shows that the fluorescence of 2 may be assigned to the emission of ligand-to-metal charge transfer (LMCT). ${ }^{31}$

Acknowledgements. This work was supported by the 973 program of the MOST (001CB108906), the National Natural Science Foundation of China (20425313, 90206040 , 20333070 and 20303021), the NSF of Fujian Province and the State Key Laboratory of Structural Chemistry (030065).

\section{References}

1. Moulton, B.; Zaworotko, M. J. Chem. Rev. 2001, 101, 1629.

2. Hagrman, P. J.; Hagrman, D.; Zubieta, J. Angew. Chem., Int. Ed. 1999, 38, 2638.

3. Robson, R. J. J. Chem. Soc., Dalton Trans. 2000, 3735.

4. Molecular Magnetic Materials, Nato ASI Series E198; Gatteschi, D.; Kahn, O.; Miller, J., Eds.; Kluwer: Dordrecht, The Netherlands, 1991.

5. Yaghi, O. M.; Li, G.; Li, H. Nature 1995, 378, 703.

6. Chen, C.; Suslick, K. S. Coord. Chem. Rev. 1993, 128, 293.

7. Li, G. H.; Shi, Z.; Xu, Y. H.; Feng, S. H. Inorg. Chem. 2003, 42, 1170.

8. Boudaren, C.; Bataille, T.; Auffredic, J.-P.; Louer, D. Solid State Sciences 2003, 5, 175.

9. Vaidhyanathan, R.; Natarajan, S.; Rao, C. N. R. Eur. J. Inorg. Chem. 2003, 1675.

10. Liu, T. F.; Sun, H. L.; Gao, S.; Zhang, S. W.; Lau, T. C. Inorg. Chem. 2003, 42, 4792.

11. Zhang, X. T.; Lu, C. Z.; Zhang, Q. Z.; Lu, S. F.; Yang, W. B.; Liu, J. C.; Zhuang, H. H. Eur. J. Inorg. Chem. 2003, 1181.

12. Millange, F.; Serre, C.; Ferey, G. Chem. Commun. 2002, 822.

13. Dai, J. C.; Wu, X. T.; Fu, Z. Y.; Hu, S. M.; Du, W. X.; Cui, C. P.; Wu, L. M.; Zhang, H. H.; Sun, R. Q. Chem. Commun. 2002, 12.

14. Delgado, F. S.; Sanchiz, J.; Ruiz-Pérez, C.; Lloret, F.; Julve, M. Inorg. Chem. 2003, 42, 5938.

15. Borghi, E. Gazz. Chim. Ital. 1987, 117, 557.

16. Sain, S.; Maji, T. K.; Mostafa, G.; Lu, T. H.; Chaudhuri, N. R. New J. Chem. 2003, 27, 185.

17. Rodriguez-Martin, Y.; Hernandez-Molina, M.; Sanchiz, J.; RuizPérez, C.; Lloret, F.; Julve, M. Dalton Trans. 2003, 2359.

18. Sain, S.; Maji, T. K.; Mostafa, G.; Lu, T. H.; Chaudhuri, N. R. Inorg. Chim. Acta 2003, 351, 12.

19. Lightfoot, P.; Snedden, A. J. Chem. Soc., Dalton Trans. 1999, 3549.

20. Hernandez-Molina, M.; Lorenzo-Lius, P. A.; Ruiz-Pérez, C.; Lloret, F.; Julve, M. Inorg. Chim. Acta 2001, 313, 87.

21. Lin, J.; Zeng, H.; Chen, J.; Wang, Q.; Wu, X. Chem. Commun. 1997, 1213.

22. Shen, H. Y.; Bu, W. M.; Liao, D. Z.; Jiang, Z. H.; Yan, S. P.; Wang, G. L. Inorg. Chem. Commun. 2000, 3, 497.

23. Maji, T. K.; Sain, S.; Mostafa, G.; Lu, T. H.; Ribas, J.; Monfort, M.; Chaudhuri, N. R. Inorg. Chem. 2003, 42, 709.

24. Rodriguez-Martin, Y.; Ruiz-Pérez, C.; Sanchiz, J.; Lloret, F.; Julve, M. Inorg. Chim. Acta 2001, 318, 159.

25. Wang, Z. X.; Zhou, X. H.; Yu, W. T.; Fu, Y. J. Z. Kristallogr-New Cryst. Struct. 2000, 215, 423.

26. Rodriguez-Martin, Y.; Hernandez-Molina, M.; Delgado, F. S.; Pasan, J.; Ruiz-Pérez, C.; Sanchiz, J.; Lloret, F.; Julve, M. Cryst. Eng. Commun. 2002, 4, 440.

27. Ruiz-Pérez, C.; Hernandez-Molina, M.; Lorenzo-Luis, P.; Lloret, F.; Cano, J.; Julve, M. Inorg. Chem. 2000, 39, 3845.

28. Xiao, X.; Xu, W.; Li, Y.; Zhang, B.; Zhu, D. Acta Cryst. 2004, $60 E, \mathrm{~m} 48$

29. Liu, J. G.; Xu, D. J. Acta Cryst. 2004, 60E, m541.

30. Butler, K. R.; Snow, M. R. J. Chem. Soc., Dalton Trans. 1976, 259.

31. Zhang, L. Y.; Liu, G. F.; Zheng, S. L.; Ye, B. H.; Zhang, X. M.; Chen, X. M. Eur. J. Inorg. Chem. 2003, 2965. 